\title{
Research on control strategy based on multi-mode switching of photovoltaic grid connected inverter
}

\author{
Zhong-Lin Zhang ${ }^{1}$,Tao Wang ${ }^{1}$, Hong Bai ${ }^{1}$, Bao-Guo $\mathrm{Li}^{2}$,Tao Cong ${ }^{2}, \mathrm{Xi} \mathrm{Li}^{\dagger}$ \\ 1. Jinzhou City Power Supply Company \\ State Grid Liaoning Electric Power Co. Ltd \\ No. 20, Jiefang Street, Guta District, Jinzhou 121000, P.R. China \\ 1980838886@qq.com. \\ 2. Department of Electrical Engineering \\ Liaoning University of Technology \\ No. 169, Shiying Street, Guta District, Jinzhou, 121001, P. R. China
}

\begin{abstract}
Aim at making the grid connected inverter controlled in a targeted manner; a control strategy based on multi-mode switching is presented in this paper. Combined with operation status of PV grid connected system, the operation of grid connected inverter can be divided into the following four kinds of operation mode, namely maximum P mode, f-P mode, V-Q mode and P-Q power mode, meanwhile, the partition condition of the model is given. Based on the four operation modes of grid connected inverter, the four control modes of inverter are defined. In the control strategy, the control idea of the operation mode inner and among the several operation models is given respectively. According to the two stage structures of single phase full-bridge inverter, application characteristics of various models are analyzed in detail, and the corresponding control strategy of grid connected inverter is given. For problem of PV grid connected system that exits in the process of operation mode switching, the corresponding control link is regarded as the feed-forward before switching mode to change the droop coefficient, achieve the smooth switching among models and eliminate the impulse caused by system. MATLAB simulation result shows the correctness of model control and effectiveness of mode switching control.
\end{abstract}

Keywords: PV grid connected inverter; Operation mode; Switching mode; Control mode.

\section{Introduction}

Maximum power mode is normal mode in PV system, Several MPPT control methods are introduced [1-4]. With the development and improvement of PV power generation system, single operation mode cannot meet the requirements of application. Active and reactive power decoupling control of inverter is realized [5], but the feedback quantity is not controlled and static errors cannot completely be eliminated. Method based on the feedback linearization theory and method joined grid voltage feedforward control are proposed [6-7]. Meanwhile, a kind of DC bus voltage and current double loop PI control algorithm is proposed [8]. It adopts voltage feed-forward control method to eliminate voltage disturbance. According to national standards of PV power 
plants connected to the grid, a certain low voltage ride through capability is needed [9]. Literature [10] is based on model predictive control method for current control inverter output support and network voltage reactive power. With PV power generation system of MPPT control and battery energy storage, a control method switching between island mode and parallel operation mode is proposed [11]. In order to improve system stability, the control method of prolapsed dual-mode is presented [12].

For better grid connected inverter control in a targeted manner, the operation mode of grid connected inverter is divided combining with operation status of photovoltaic grid connected system, and a control strategy of switching photovoltaic grid connected inverter mode is proposed.

\section{Operation Mode of PV Grid Connected Inverter}

According to actual operation of power grid, in order to PV grid connected power generation system adapting to the change of power grid, grid connected inverter operation is divided into four operating modes in detail, namely maximum power output mode( $\mathrm{P}$ mode), frequency-active mode(f-P mode), voltage-reactive mode( $\mathrm{V}-\mathrm{Q}$ mode) and active-reactive mode( $\mathrm{P}-\mathrm{Q}$ mode).

(1) $\mathrm{P}$ mode refers to the work mode of inverter to track the maximum power output of PV. Inverter, under the "Regular" mode, is generally regarded as voltage and frequency of power grid are within normal range.

(2) f-P mode is that when frequency fluctuation is caused by the failures of power grid side, active power output of the inverter can be directly affected.

(3) V-Q power model is that when the grid side fault causes the over-limit voltage, PV grid connected power generation system is able to output power to the grid side and transmit reactive power quickly.

(4) P-Q mode is that PV grid connected power generation system gives a constant active power and reactive power. It realizes the constant active power and reactive power are transmitted to grid by using f-P and V-Q mode.

\section{Control Strategy of PV Grid Connected Inverter}

According to the current value of power grid frequency and voltage, it uses the corresponding control strategy with active power and reactive power real-time adjustment of PV grid connected power generation system to maintain the normal operation of power grid. 


\subsection{The condition of the inverter operation mode division}

According to overall requirement and standard of PV grid control system, voltage and frequency variation is the condition of the inverter operation mode division.

(1) Inverter operation mode is based on the voltage deviation of grid system, according to power quality of power supply voltage deviation(GB12325), voltage fluctuation range is set as $\pm 5 \%$.

(2) In standard, PV grid connected power system meet the grid connected operation conditions, frequency deviation should be kept in the range of $50 \pm 0.2 \mathrm{~Hz}$.

\subsection{Division of inverter operation mode}

PV power generation system is usually divided into two operation modes which are on-grid and off-grid. According to the operation state of PV grid connected power system, the inverter operation mode is divided into four modes in this paper. The purpose is to make the grid connected inverter more effective in controlling and maximize the efficiency of PV power generation system. The control mode of grid connected inverter is connected with the operation mode of grid connected inverter, and the operation mode of grid connected inverter is classified several categories according to the division conditions:

(1) P mode, $U \in(1 \pm 5 \%) U_{0}, f \in(50 \pm 0.2) \mathrm{Hz}$.

(2) f-P mode, $U \in(1 \pm 5 \%) U_{0}, f \notin(50 \pm 0.2) \mathrm{Hz}$.

(3) V-Q mode, $U \notin(1 \pm 5 \%) U_{0}, f \in(50 \pm 0.2) \mathrm{Hz}$.

(4) P-Q mode, $U \notin(1 \pm 5 \%) U_{0}, f \notin(50 \pm 0.2) \mathrm{Hz}$.

\subsection{Multi-mode control strategy of inverter}

The four inverter operation modes is corresponding to four inverter control modes, namely $\mathrm{P}$ control mode, f-P control mode, V-Q control mode and P-Q control mode. Inverter control strategy should include mode control of inner operation modes and mode switching between operation modes.

\section{Simulation Analysis}

In order to verify the control strategy proposed in this paper, the partial operation mode and the corresponding control mode are simulated by the simulation system. A two-stage full bridge inverter is selected. Pre-stage DC-DC converter completes the maximum power point tracking, and then post-stage DC-AC is regulated.

(1)P mode simulation 
The simulation results of output current and voltage waveform are shown in Figure 3, vertical coordinate is voltage and current (V/A), grid voltage is $311 \mathrm{~V}$, and value of grid current is $9.6 \mathrm{~A}$.

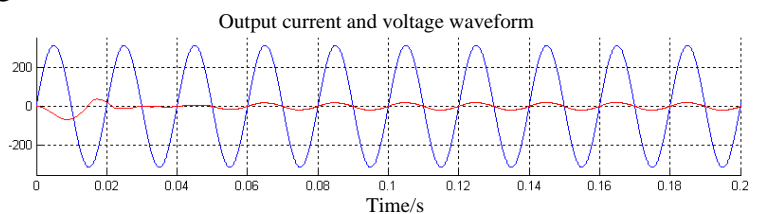

Fig. 3. Output current and voltage waveform

Active power and reactive power output of the simulation is shown in Figure 4,output power of PV system closes to $3 \mathrm{KW}$ when running to steadystate under $\mathrm{P}$ mode.

A photovoltaic cell simulation output is $3.2 \mathrm{KW}$, output power of the inverter is slightly less than that of the photovoltaic cell. The purpose to track the maximum power point output is achieved, and output reactive power is 0Var.

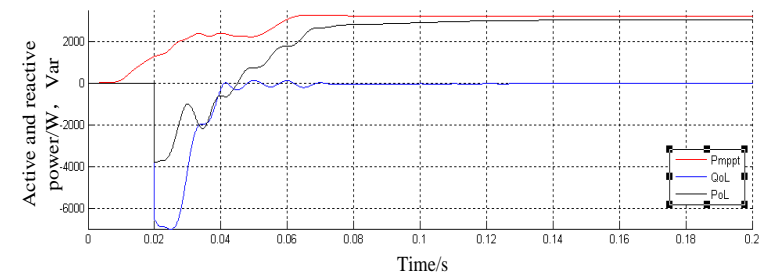

Fig. 4. Simulation waveform of PV cell output power, inverter output power (2) Simulation switch between P mode and f-P mode According to change of frequency, inverter changes active power output. Based on the frequency change condition, the switching simulation between the f-P mode and the $\mathrm{P}$ mode is given. When $\mathrm{f}<50.02 \mathrm{~Hz}$, it does not meet mode switching condition, operation mode of inverter will not change. Only when the frequency $\mathrm{f}>50.02 \mathrm{~Hz}$, the operation mode of the inverter can be switched between f-P mode and $\mathrm{P}$ mode. Simulation results show that when frequency is less than $50.2 \mathrm{~Hz}$ the output active power of inverter is not changed and equal to max output active power.

Based on test data, the cubic fitting curve of f-P is shown in Figure 5. The curve shows that the relationship of $\mathrm{f}-\mathrm{P}$ tends to be linear. 


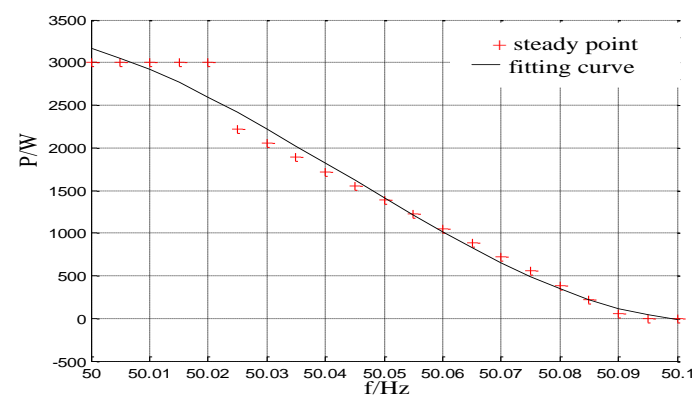

Fig. 5. Three fitting curves of frequency and active power

According to the characteristics of $\mathrm{f}-\mathrm{P}$, droop coefficient kp shows the linear relationship between active power and frequency. To achieve mode switching, it is necessary to ensure that the slope $\mathrm{kp}$ is linear so that the switching process is smooth. Simulation results show that active power does linear change after frequency changing after $0.225 \mathrm{~S}$. Frequency change is out of the range of the standard at $0.223 \mathrm{~S}$ which drives the step change of output active power. When the mode is switched, the switching process is completed smoothly as shown in Figure 6.

Similarly, in the process of $\mathrm{f}-\mathrm{P}$ mode to $\mathrm{P}$ mode, simulation waveform of active power output is shown in figure 7 . Active power of inverter will increase or decrease with the change of frequency. At $0.138 \mathrm{~S}$, the change of frequency is beyond the frequency standard, then inverter operation mode changes, and active power begins to rise to $3 \mathrm{~kW}$.

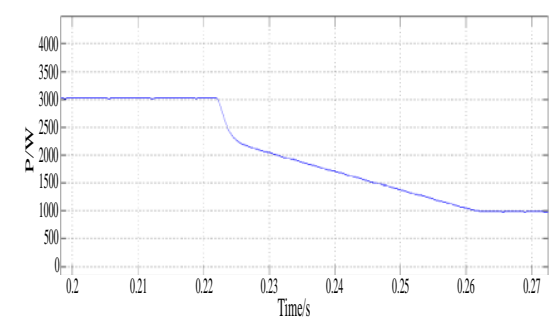

Fig. 6. P mode to f-P mode switching active power output waveform

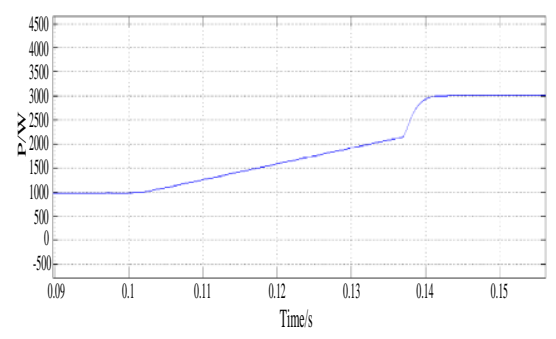

Fig. 7. f-P mode to $\mathrm{P}$ mode power output waveform

\section{Conclusion}

Control strategy based on multi-mode switching as well as determinant conditions of different operation mode and mode division of grid connected inverter are proposed in this paper. Based on decoupling control technology and improved droop control technology can be used to complete mode switching between operation modes and mode control of inner operation modes. Especially, the transient pulse caused by mode-switching can be restrained with 
variable droop coefficient. Simulation results indicate the correctness of mode division and effectiveness of multi-mode switching control.

\section{References}

1. L. Zhou, J. Wu, Q. Li, K. Guo 2008 photovoltaic array maximum power point tracking control method [J] (High voltage technology) pp 1145-115

2. L.b. Wu, Z.M. Zhao, J.Z. Liu, J.Y. Wang, Q.Li 2006 Implementation of a Single-Stage Three-Phase Grid-Connected Photovoltaic System With Reactive Power Compensation [J] (Transactions of China Electro technical Society) pp 28-32

3. S.J. Liu, S.Zhuang X.C. Xi 2014 Research on the control method of current disturbance observers for photovoltaic grid-connected inverters [J] (Proceedings of the CSEE) pp 5811-5818

4. X.Z.Li, J.P.Sun. 2012 Simulation of auto-adapted step size incremental conductance method MPPT control based on segmented numerical approximation [J] (Acta Energiae Solaris Sinica) pp 1164-1170

5. Bouchafaa F, Beriber D, Boucherit M S 2010 Modeling and control of a gird connected PV generation system[C] (Proceedings of 18th Mediterranean Conference on Control \& Automation. Arlington, TX, USA) pp 315-320

6. F. Delfino, G.B. Denegri, M. Invernizzi, R. Procopio. 2012 Feedback linearization oriented approach to $\mathrm{Q}-\mathrm{V}$ control of grid connected photovoltaic units [J] (IET Renewable Power Generation) pp 324-339

7. T.Q. Cao, J.P. Xu, Q. Qi, J. Wang. 2012 Control of grid-connected singlephase photovoltaic inverter $[\mathrm{J}]$ (Electric Power Automation Equipment) pp 133-136

8. P.Yang, X.S.Zeng. 2012 Research on control arithmetic of the single-phase grid-connected photovoltaic system[J] (Power Electronics) pp 48-51

9. STATE Grid Corporation of China 2011 Technical principle for connecting $\mathrm{PV}$ power station to grid[S]

10. L.H. Jia, Y.Q. Zhu, X.Y.Sun, Y.S Wang.. 2015 A control method of low voltage ride through for photovoltaic plant based on model current predictive control [J]. (Automation of Electric Power Systems) pp 68-74

11. Sarina Adhikari, Fangxing Li. 2014 Coordinated V-f and P-Q Control of Solar Photovoltaic Generators With MPPT and Battery Storage in Microgrids [J] (IEEE TRANSACTIONS ON SMART GRID) pp 12701281

12. X.F.Sun, H.H.Li. 2016 Control method of dual mode droop for inverters $[\mathrm{J}]$ Proceedings of the CSEE pp 507-515 